\section{Case Reports in Ophthalmology}

Case Rep Ophthalmol 2021;12:41-47

DOI: 10.1159/000510346

Published online: January 11, 2021
(C) 2021 The Author(s)

Published by S. Karger AG, Basel www.karger.com/cop

\title{
Efficacy of Femtosecond Laser-Assisted Cataract Surgery for Cataracts due to Atopic Dermatitis
}

\author{
Kenichiro Yamazaki ${ }^{a}$ Junko Yoneyama ${ }^{a}$ Takahiko Hayashi ${ }^{b}$ \\ Ryuta Kimoto $^{a}$ Yuko Shibata $^{a}$ Tatsuya Mimurac \\ a Omiya Nanasato Eye Institute, Saitama City, Japan; bepartment of Ophthalmology, \\ Yokohama Minami Kyosai Hospital, Yokohama City, Japan; 'Department of \\ Ophthalmology, Teikyo University, Tokyo, Japan
}

\section{Keywords}

Atopic cataract · Cataract surgery · Femtosecond laser-assisted cataract surgery

\begin{abstract}
We retrospectively evaluated the efficacy and safety of femtosecond laser-assisted cataract surgery (FLACS) for cataracts due to atopic dermatitis, which are often complicated by intumescent white cataract (IWC) and subcapsular fibrosis. Thirty-seven eyes of 30 cataract patients diagnosed with atopic dermatitis were included in the study. Nine eyes had IWC, and 13 eyes had anterior subcapsular fibrosis characteristic of atopic cataracts. Free-floating capsulotomy was achieved in 32 eyes (86\%). Three eyes with fibrosis extending across the line of capsulotomy required manual excision. Incomplete capsulotomies due to anterior capsular tags were present in 4 eyes in the IWC group, which was significantly higher compared to non-IWC cases $(p<0.05)$. Radial anterior capsular tear, vitreous loss, and intraocular lens dislocation did not occur in any of the cases. FLACS can be performed safely in atopic cataract despite the presence of anterior subcapsular fibrosis and/or IWC.




\section{Case Reports in Ophthalmology}

\begin{tabular}{l|l}
\hline DOI: 10.1159/000510346 & $\begin{array}{l}\text { (c) } 2021 \text { The Author(s). Published by S. Karger AG, Basel } \\
\text { www.karger.com/cop }\end{array}$ \\
\hline
\end{tabular}

Yamazaki et al.: Efficacy of Femtosecond Laser-Assisted Cataract Surgery for Cataracts due to Atopic Dermatitis

\section{Introduction}

Atopic dermatitis (AD) is a common type of skin disease in Japan and other Eastern Asian countries but is not as prevalent in the rest of the world. In Japan, up to $12 \%$ of the population are diagnosed with $\mathrm{AD} \mathrm{[1],} \mathrm{and} 6 \%$ in the United States [2]. One of the main ocular complications with $\mathrm{AD}$ is the development of atopic cataracts in relatively young patients. Atopic cataracts vary in clinical findings, with intumescent white cataracts (IWCs) and characteristic anterior subcapsular fibrosis commonly observed. In Japan, cataract patients undergoing surgery at a relatively young age are often affected by AD [3]. Currently, there are no definitive therapies for $\mathrm{AD}$, although topical and systemic immunosuppression provides temporary remission. However, long-term use of corticosteroids is difficult due to complications such as cataracts and glaucoma.

It is unclear how $\mathrm{AD}$ patients develop the characteristic atopic cataracts. A previous report hypothesized that atopic cataract development is correlated with oxidative damage of the lens and related to chronic inflammation [4]. Nagaki et al. [3] reported that the incidence of cataract is higher in AD patients with facial involvement. This suggests that scratching of itchy lesions may be associated with cataract formation. Amemiya et al. [5] reported that 25\% of atopic cataract patients showed anterior subcapsular fibrosis. The mechanism of anterior subcapsular fibrosis formation is unclear; however, histopathology shows alpha-smooth muscle actin-reactive elongated cells within the lesion [6]. Subcapsular fibrosis can complicate continuous curvilinear capsulorrhexis (CCC) and may lead to radial tears. IWCs also have a high risk for incomplete CCC, with frequent capsular tears. We evaluated the efficacy of femtosecond laser-assisted cataract surgery (FLACS) in the treatment of atopic cataracts.

\section{Case Presentation}

Thirty-seven eyes of 30 atopic cataract patients (male: 34 eyes of 27 patients, female: 3 eyes of 3 patients, average age $48.1 \pm 12$ years) treated with FLACS (LenSx, Alcon, Fort Worth, TX, USA) and intraocular lens (IOL) implantation between June 2012 and December 2016 at the Omiya Nanasato Eye Institute were retrospectively examined in this study. Atopic cataract was diagnosed by a previous history of $\mathrm{AD}$ diagnosed by a dermatologist and by ruling out other possible causes of cataract formation.

This study conformed to the tenets of the Declaration of Helsinki, and written informed consents were obtained from all patients prior to surgery. The study was approved by the institutional Ethics Committee. All surgeries were performed by a single surgeon (K.Y.) using FLACS to perform capsulotomy, corneal incisions, and lens fragmentation. One eye had a history of LASIK, and 1 eye had previous scleral buckling. Two cases of mild keratoconus with no corneal hydrops were also included.

Anterior capsulotomies of $4.8 \mathrm{~mm}$ diameter were done with laser energy set at $6.00 \mu \mathrm{J}$ with spot separation of $5 \mu \mathrm{m}$ and layer separation of $4 \mu \mathrm{m}$. Offset was set at $300 \mu \mathrm{m}$ above and $400 \mu \mathrm{m}$ below the anterior capsule. Lens fragmentation was done by 3 perpendicular planes divided into 6 fragments. Fragmentation diameter was set at $4.7 \mathrm{~mm}$, with offset parameters set at $500 \mu \mathrm{m}$ below the anterior capsule and 1,000 $\mu \mathrm{m}$ above the posterior capsule. Main corneal incisions were made with a $2.3-\mathrm{mm}$ exterior and 2.2-mm interior lip. If visibility was hindered due to an IWC, indocyanine green was used to stain the anterior capsule after removing liquefied lens material by irrigation and aspiration. In cases with capsular tags, the

\section{Karger'=}




\section{Case Reports in Ophthalmology}

Case Rep Ophthalmol 2021;12:41-47 DOI: $10.1159 / 000510346$

(c) 2021 The Author(s). Published by S. Karger AG, Basel www.karger.com/cop

Yamazaki et al.: Efficacy of Femtosecond Laser-Assisted Cataract Surgery for Cataracts due to Atopic Dermatitis

anterior capsule was carefully removed with anterior capsule forceps. All cases were implanted with diffractive multifocal IOLs, excluding 1 eye with irregular astigmatism due to keratoconus, in which a monofocal IOL was implanted.

A free-floating capsulotomy was achieved in 32 eyes (86\%). Nine eyes had IWC. Among these eyes, 6 had no lens nucleus, while 2 eyes had grade 5 and 1 eye had grade 3 nuclear cataracts. In 6 eyes with intumescent cataracts, lens material leaked into the anterior chamber during femtosecond laser emission (shown in Fig. 1a, b). Incomplete capsulotomies due to anterior capsular tags were present in 4 eyes in the IWC group, which was significantly higher compared to non-IWC cases $(p<0.05)$. Hard anterior subcapsular fibrosis typical of atopic cataract was observed in 13 eyes, including 3 eyes with fibrosis extending across the line of capsulotomy requiring manual excision (shown in Fig. 1c, d). Scissors were effective in excising fibrotic lesions without causing radial tears during capsular removal. The scleral buckling case had weak zonules; however, a free-floating capsulotomy was achieved and central fixation of the IOL was possible. None of the cases suffered from radial anterior capsular tear (shown in Fig. 2), vitreous loss, or IOL dislocation. Average corneal endothelial density was $2,624 \pm 206 / \mathrm{mm}^{2}$ preoperatively and $2,425 \pm 360 / \mathrm{mm}^{2}$ postoperatively ( $5.8 \%$ average decrease).

\section{Discussion}

Diagnosis of atopic cataract is not difficult, as most of our cases suffered from severe skin lesions with typical anterior subcapsular fibrosis and IWC. IWC with or without subcapsular fibrosis can cause incomplete capsulorrhexis during manual surgery, which may lead to decentration of the IOL that will affect visual quality especially with multifocal IOLs. The advantage of using FLACS is that the success rate of a free-floating capsulotomy is close to $100 \%$. For example, previous reports show success rates to be up to $96 \%$ with the LenSx system [7]. This percentage is reported to decrease in IWCs, such as in the report by Conrad-Hengerer et al. [8], where incomplete capsulotomy buttons occurred in 3 eyes and an adherent tongue-like capsule adhesion in 9 eyes out of a total of 25 eyes. In our study, free-floating capsulotomy was successful in 27 out of 28 eyes (96.4\%) without intumescent cataracts. On the other hand, 4 out of 9 intumescent cases had incomplete capsulotomies. In all 4 cases, lens material leaked into the anterior chamber, which may have led to shifting of the anterior capsular position, leading to an incomplete cut. In the successful 5 cases, leakage of lens material was not observed, suggesting that free-floating capsulotomies can be achieved in such cases without complications. This shows that an atopic cataract that has become intumescent will greatly affect the success rate of capsulotomy during FLACS. Similar results were reported by Titiyal et al. [9] who found that the risk of residual capsular adhesions was associated with the release of white milky fluid. Schultz et al. [10] introduced a 2-stage capsulotomy technique for FLACS in intumescent cataracts. Such a technique may be an option for cases with lysis of lens material.

Anterior subcapsular fibrosis can also lead to complications during surgery of atopic cataracts. During manual CCC, radial tears may result from fibrosis of the anterior capsule. In our case series, 13 eyes had anterior subcapsular fibrosis. Three of these cases had fibrosis extending across the line of capsulotomy. While the laser successfully cut the anterior capsule in these eyes, the underlying fibrosis was left intact. Careful excision of the fibrotic lesion using scissors was performed without difficulty.

\section{Karger'=}




\section{Case Reports in Ophthalmology}

FLACS is still a relatively new technology which may require additional cost, and therefore, care is required to obtain informed consent before surgery. However, since we successfully implanted IOLs in the bag with optimal centration in all 30 cases of atopic cataract undergoing surgery, FLACS seems to have several advantages for treating atopic cataracts compared to manual surgery. In conclusion, FLACS is a good option for complicated atopic cataracts.

\section{Statement of Ethics}

This study conformed to the tenets of the Declaration of Helsinki, and written informed consents were obtained from all patients prior to surgery. The study was approved by the institutional Ethics Committee.

\section{Conflict of Interest Statement}

The authors have no conflicts of interest to declare.

\section{Funding Sources}

There are no funding sources for this study.

\section{Author Contributions}

All authors attest that they meet the current ICMJE criteria for authorship and approve the final version of the manuscript. K.Y.: Drafting the work, conception of the study, data interpretation, manuscript writing, editing, and revision. J.Y.: Literature search, patient management, and revision of the manuscript. T.H.: Conception of the study, data interpretation, and manuscript editing. R.K.: Patient management, conception of the study, literature search, and analysis of data. Y.S.: Patient management, analysis and interpretation of data, and revision of the manuscript. T.M.: Literature search, analysis and interpretation of data, and revision of the manuscript.

\section{References}

1 Furue M, Chiba T, Takeuchi S. Current status of atopic dermatitis in Japan. Asia Pac Allergy. 2011 Jul;1(2):6472.

2 Hanifin JM, Reed ML; Eczema Prevalence and Impact Working Group. A population-based survey of eczema prevalence in the United States. Dermatitis. 2007 Jun;18(2):82-91.

3 Nagaki Y, Hayasaka S, Kadoi C. Cataract progression in patients with atopic dermatitis. J Cataract Refract Surg. 1999 Jan;25(1):96-9.

4 Bair B, Dodd J, Heidelberg K, Krach K. Cataracts in atopic dermatitis: a case presentation and review of the literature. Arch Dermatol. 2011 May;147(5):585-8.

5 Amemiya T, Matsuda H, Uehara M. Ocular findings in atopic dermatitis with special reference to the clinical features of atopic cataract. Ophthalmologica. 1980;180(3):129-32.

\section{Karger'=}


Yamazaki et al.: Efficacy of Femtosecond Laser-Assisted Cataract Surgery for Cataracts due to Atopic Dermatitis

6 Shu DY, Ong K, Lovicu FJ. Histopathology of Subcapsular Cataract in a Patient with Atopic Dermatitis. Optom Vis Sci. 2017 Feb;94(2):270-6.

7 Roberts TV, Lawless M, Bali SJ, Hodge C, Sutton G. Surgical outcomes and safety of femtosecond laser cataract surgery: a prospective study of 1500 consecutive cases. Ophthalmology. 2013 Feb;120(2):227-33.

8 Conrad-Hengerer I, Hengerer FH, Joachim SC, Schultz T, Dick HB. Femtosecond laser-assisted cataract surgery in intumescent white cataracts. J Cataract Refract Surg. 2014 Jan;40(1):44-50.

9 Titiyal JS, Kaur M, Singh A, Arora T, Sharma N. Comparative evaluation of femtosecond laser-assisted cataract surgery and conventional phacoemulsification in white cataract. Clin Ophthalmol. 2016 Jul;10:1357-64.

10 Schultz T, Dick HB. Laser-assisted mini-capsulotomy: a new technique for intumescent white cataracts. J Refract Surg. 2014 Nov;30(11):742-5. 


\section{Case Reports in Ophthalmology}

\begin{tabular}{l|l}
\hline Case Rep Ophthalmol 2021:12:41-47 \\
\hline DOI: 10.1159/000510346 & $\begin{array}{l}\text { c 2021 The Author(s). Published by S. Karger AG, Basel } \\
\text { www.karger.com/cop }\end{array}$ \\
\hline
\end{tabular}

Yamazaki et al.: Efficacy of Femtosecond Laser-Assisted Cataract Surgery for Cataracts due to Atopic Dermatitis
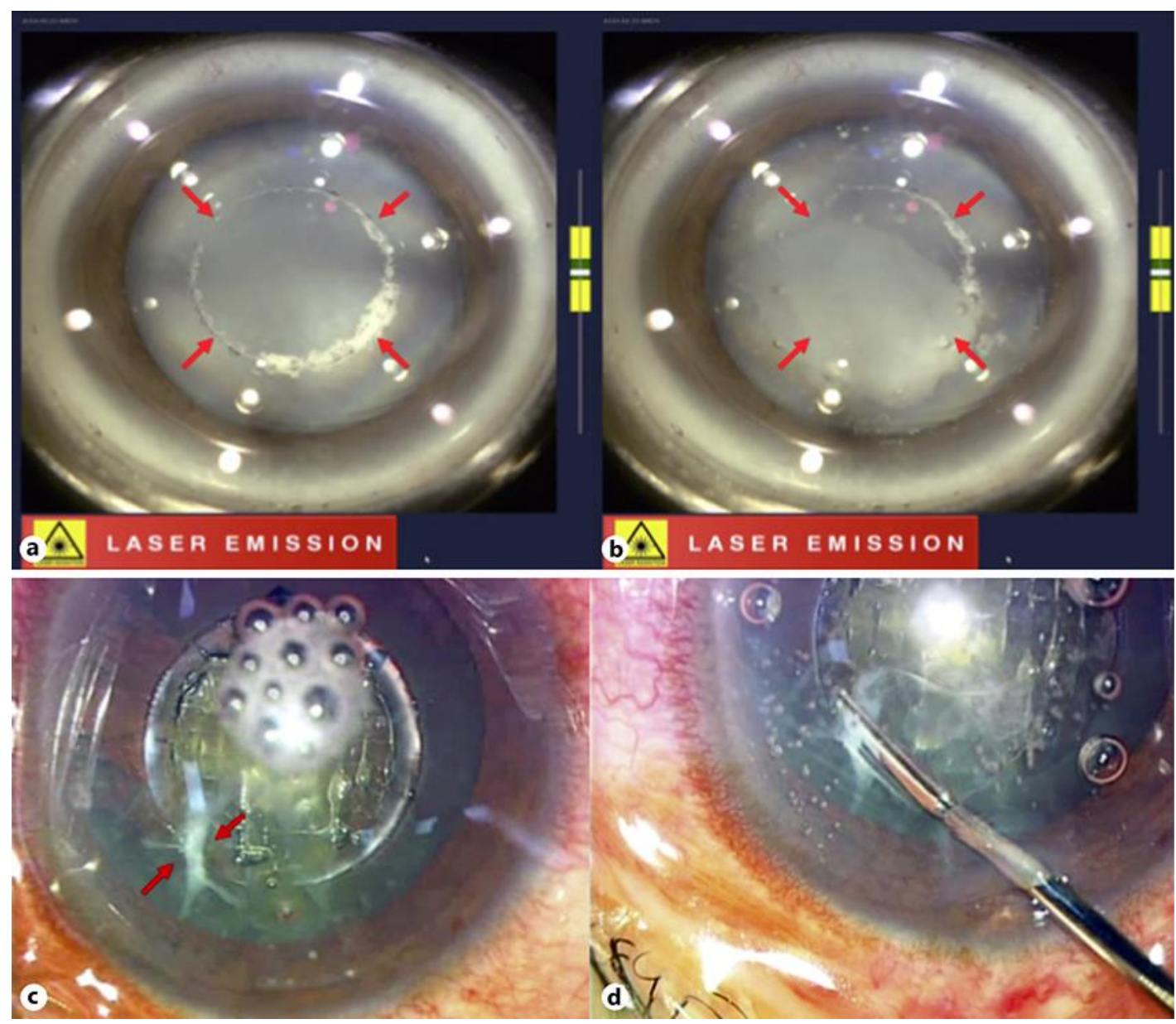

Fig. 1. a Left eye of a 21-year-old male, the youngest patient in the study. Intra-operative image of FLACS during the initial stages of capsulotomy. Arrows indicate capsulotomy margin. $\mathbf{b}$ Leakage of liquefied lens material (lower right arrow), causing poor visibility of the anterior chamber and capsulotomy margin. Decreased lens volume causes a shift in the anterior capsule position leading to incomplete capsulotomy. c 73-year-old male with anterior subcapsular fibrosis. Arrows show margin of the capsulotomy crossing the area of fibrosis. $\mathbf{d}$ Since the fibrotic lesion was attached to the anterior capsular flap, scissors were used to excise the lesion prior to removal of the flap. 


\section{Case Reports in Ophthalmology}

\begin{tabular}{l|l}
\hline Case Rep Ophthalmol 2021;12:41-47 \\
\hline DOI: 10.1159/000510346 & $\begin{array}{l}\text { ( ) 2021 The Author(s). Published by S. Karger AG, Basel } \\
\text { www.karger.com/cop }\end{array}$ \\
\hline
\end{tabular}
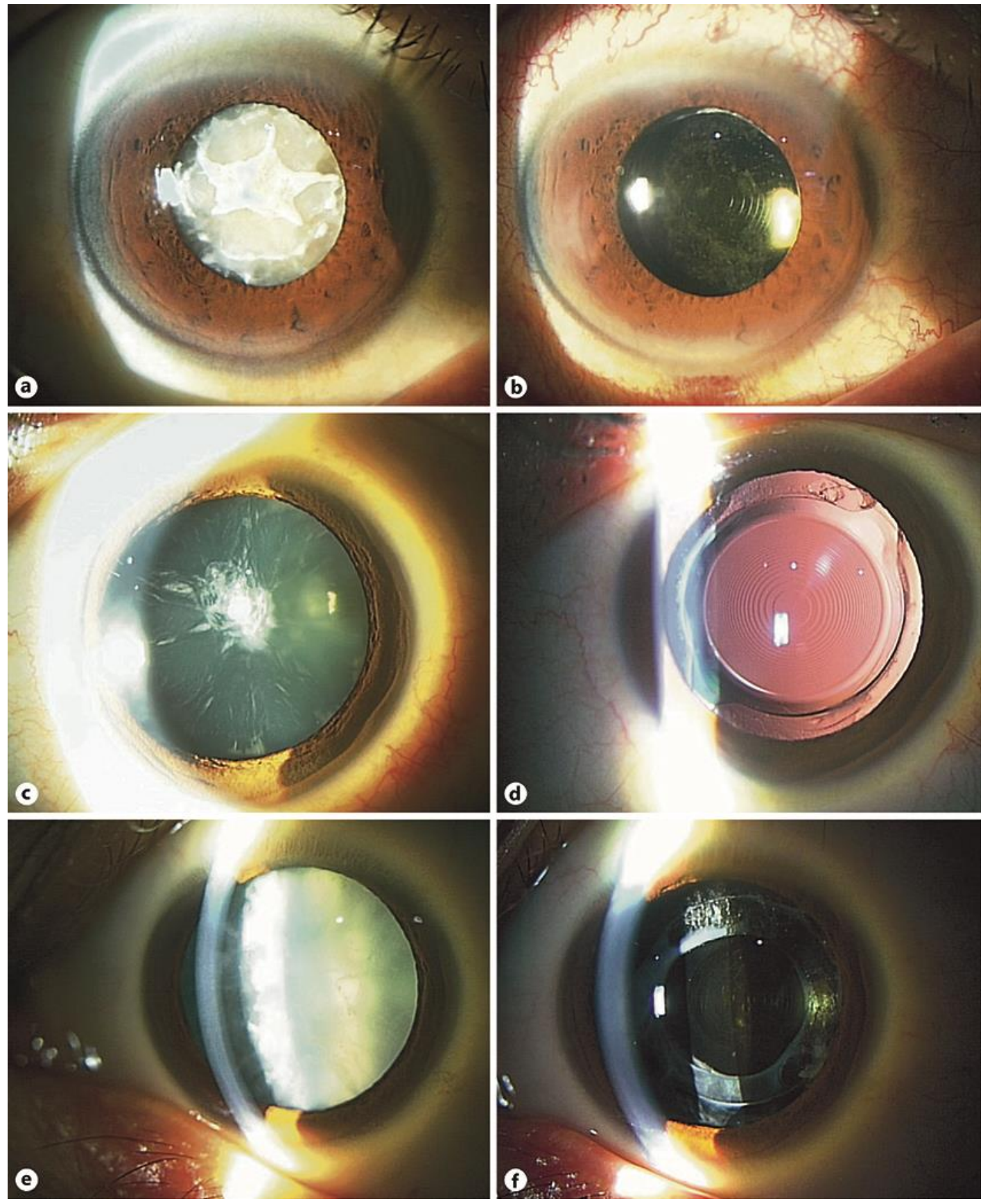

Fig. 2. Preoperative (a) and postoperative (b) photograph of the right eye of a 53-year-old male with anterior subcapsular fibrosis and a brown cataract. Preoperative (c) and postoperative (d) photograph of the left eye of a 40-year-old female with anterior subcapsular fibrosis. Preoperative (e) and postoperative (f) photograph of the right eye of a 41-year-old male with an IWC. All cases show complete capsulotomy with good centration of the IOL. 